\title{
Microstructure and Its Influence on the Mechanical Properties of Ni-28W-6Cr-Based Alloy-Welded Joints by GTAW
}

\author{
Shuang-Jian Chen ${ }^{1} \cdot$ Xiang-Xi Ye $^{1} \cdot$ D. K. L. Tsang ${ }^{1} \cdot$ Li Jiang $^{1} \cdot$ Chao-Wen $\mathrm{Li}^{1} \cdot \mathrm{Kun} \mathrm{Yu}^{1} \cdot \mathrm{Zhi}^{-J u n} \mathrm{Li}^{1}$
}

Received: 24 September 2018 / Revised: 5 December 2018 / Published online: 27 February 2019

(c) The Chinese Society for Metals (CSM) and Springer-Verlag GmbH Germany, part of Springer Nature 2019

\begin{abstract}
Microstructure and mechanical properties of Ni-28W-6Cr alloy-welded joints produced by gas tungsten arc welding were investigated in this work. Results showed that original fine-grain base metal near fusion line totally transformed into coarse heat affected zone after welding. Carbides with different shapes were found in the weld metal and base metal, which all were determined as $\mathrm{M}_{6} \mathrm{C}$ carbides. In comparison with carbides in base metal, $\mathrm{M}_{6} \mathrm{C}$ carbides in weld metal are rich in $\mathrm{Si}$ and $\mathrm{Cr}$ but deficient in W. Moreover, $\mathrm{M}_{6} \mathrm{C}$ carbides are extremely scarce and hard to be detected in weld metal. Mechanical tests show that the hardness value of weld metal is only about $60 \%$ of base metal; the yield strength and tensile strength of welded joint are much lower than those of base metal due to the absence of carbides in weld metal.
\end{abstract}

Keywords Welding $\cdot \mathrm{Ni}-\mathrm{W}-\mathrm{Cr}$ alloy $\cdot$ Carbides $\cdot$ Microstructure $\cdot$ Hardness $\cdot$ Tensile properties

\section{Introduction}

Recent years, interests in molten salts are increasing owning to their high thermal conductivities, low pressure, and excellent chemical stability at high temperature, which have been applied in various fields [1-3], such as molten salt reactor (MSR), heat transfer facilities, and hydrogen production equipment. However, it poses critical challenge for structure materials used in molten salts, which needs both excellent mechanical properties and corrosion resistance properties at elevated temperature [4]. To date, Hastelloy $\mathrm{N}$ alloy (70wt\% Ni-17wt\%Mo-6wt\%Cr) is the only successful alloy used in molten salt environment, developed by Oak Ridge National Laboratory for MSR in 1950-1960s [5, 6]. Unfortunately, its maximum temperature limit is $704{ }^{\circ} \mathrm{C}$, as for applications like a reactor-to-hydrogen-production-plant heat transfer system, the temperature of the hot side exceeds

Available online at http://link.springer.com/journal/40195

Xiang-Xi Ye

yexiangxi@sinap.ac.cn

$\triangle$ Zhi-Jun Li

lizhijun@sinap.ac.cn

1 Center for Thorium Molten Salt Reactor System, Shanghai Institute of Applied Physics, Chinese Academy of Sciences, Shanghai 201800, China above $800{ }^{\circ} \mathrm{C}[5,7]$. Recently, a Ni-28W-6Cr-based superalloy has been developed by replacing the main hardener Mo of Hastelloy $\mathrm{N}$ alloy with more effective element W, which is expected to be used as structural materials at the operation temperature above $800{ }^{\circ} \mathrm{C}[7,8]$. In addition, it has been demonstrated that this alloy maintains good tensile strength and ductility at room temperature [9]. Liu et al. [7] investigated the effect of $\mathrm{W}$ content on the mechanical properties of $\mathrm{Ni}-\mathrm{xW}-6 \mathrm{Cr}$, and concluded $\mathrm{Ni}-\mathrm{xW}-6 \mathrm{Cr}$ alloys with $\mathrm{W}$ content from 27.7 to $34 \mathrm{wt}$. \% possess the best mechanical performance. However, there are still many challenges in application of $\mathrm{Ni}-\mathrm{W}-\mathrm{Cr}$ alloy, one of which is the welding issues. It is well known that welded joints are normally the weakest part for welding structure and most structure failure occurs here [10-12]. 316L stainless steel are the major structural materials in nuclear power plants, welding process leaded a higher mainly stress corrosion cracking (SCC) in HAZ than base metal and caused mainly fracture in HAZ [13]. Study on welded Haynes 282 nickel-based superalloy showed that intergranular heat affected zone (HAZ) cracking is easily observable due to a higher cracking susceptibility than that in base metal and weld metal in the as-welded joint [14]. As a representative $\mathrm{Ni}-\mathrm{W}-\mathrm{Cr}$ alloy, study on the welding solidification behavior of Haynes $230(\mathrm{Ni}-14 \mathrm{~W}-22 \mathrm{Cr}$ ) alloys by the Varestraint tests showed that it has a high solidification cracking susceptibility because of the partitioning of $\mathrm{Cr}$ and $\mathrm{W}$ to solidification boundaries and the subsequent 
Table 1 Chemical composition of $\mathrm{Ni}-28 \mathrm{~W}-6 \mathrm{Cr}$ alloy

\begin{tabular}{lllllllll}
\hline Element & $\mathrm{Si}$ & $\mathrm{Cr}$ & $\mathrm{W}$ & $\mathrm{Fe}$ & $\mathrm{C}$ & $\mathrm{Mn}$ & $\mathrm{P}, \mathrm{S}$ & $\mathrm{Ni}$ \\
\hline Content (wt\%) & 0.31 & 6.85 & 27.91 & 0.601 & 0.04 & 0.34 & 0.004 & $\mathrm{Bal}$. \\
\hline
\end{tabular}

depression of the solidification temperature locally along those boundaries [15]. In addition, thermal fatigue tests on the welded joint of Haynes 230 alloy suggested cracks first appeared at the center of weld and propagate because of the difficulty to accommodate of plastic deformation caused by the repeated thermal shocks [9]. Furthermore, high W content can also bring some challenging issues in welding and limit a wider application of Ni-W-Cr alloys [16, 17]. Intrinsically, addition of refractory metals such as $\mathrm{W}$ into Ni-base alloy can widen the solidification temperature range of the alloy and lead to cracking during the welding process [18].

Considering the inevitable usage of welding technology in engineering applications and the complexity and uncertainty exerted by welding process on the metallic materials, especially for a very new developed $\mathrm{Ni}-28 \mathrm{~W}-6 \mathrm{Cr}$ based superalloy, it is essential to evaluate the microstructure evolution and mechanical properties of welded joint in prior to application. To date, no results have been reported on the studies of nickel alloy-welded joints with high W content $(\mathrm{W}>20 \%$ ) including $\mathrm{Ni}-28 \mathrm{~W}-6 \mathrm{Cr}$ alloy. In this work, $\mathrm{Ni}-28 \mathrm{~W}-6 \mathrm{Cr}$ alloy was first welded using gas tungsten arc welding (GTAW), and then, microstructure of welded joint was characterized, followed by investigation on the relationship between the microstructure evolution and the mechanical performance.

\section{Experimental Procedures}

\subsection{Materials}

The chemical compositions of the Ni-28W-6Cr alloy in weight percent (wt\%) are shown in Table 1. An ingot of Ni-28W-6Cr alloy was fabricated by vacuum induction melted, and then forged at $1150{ }^{\circ} \mathrm{C}$ into a bar with a diameter of $45 \mathrm{~mm}$. Subsequently, solid-solution treatment of the bar was carried out at $1260{ }^{\circ} \mathrm{C}$ for $0.5 \mathrm{~h}$, followed by water quenching. The sample pieces with a size of $100 \mathrm{~mm} \times 40 \mathrm{~mm} \times 4 \mathrm{~mm}$ were cut from the bar. GTAW was applied without filler wire. The detailed welding parameters are presented in Table 2.

\subsection{Characterization Methods}

Microstructure of the welded joint was characterized on a Zeiss M2m optical microscope (OM) and a Zeiss LEO 1530VP scanning electron microscope (SEM) equipped with an Oxford electron backscattered diffraction (EBSD)
Table 2 Welding parameters

\begin{tabular}{llllll}
\hline $\begin{array}{l}\text { Current } \\
(\mathrm{A})\end{array}$ & $\begin{array}{l}\text { Welding } \\
\text { speed } \\
(\mathrm{mm} / \mathrm{min})\end{array}$ & $\begin{array}{l}\text { Pulse } \\
\text { frequency } \\
(\mathrm{Hz})\end{array}$ & $\begin{array}{l}\text { Peak } \\
\text { pulse } \\
\text { duration } \\
(\%)\end{array}$ & $\begin{array}{l}\text { Base/peak } \\
\text { pulse } \\
\text { value }(\%)\end{array}$ & $\begin{array}{l}\text { Gas flow } \\
\text { rate (L/ } \\
\text { min) }\end{array}$ \\
\hline 150 & 100 & 2.5 & 50 & 50 & 15 \\
\hline
\end{tabular}

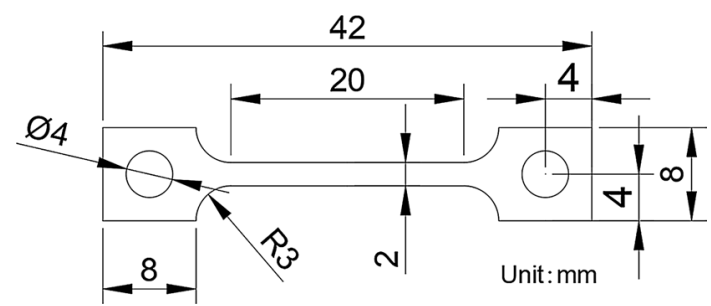

Fig. 1 Dimensions of the tensile specimens

system. Alloy phases were analyzed by Bruker D8 Advance $\mathrm{X}$-ray Diffraction (XRD) machine with a $\mathrm{CuK \alpha} 1$ radiation source $(\lambda=1.5406 \AA)$ conditioned by two $2.5^{\circ}$ Soller slits and a $0.025 \mathrm{~mm}$ Ni mask. The structures and chemical compositions of precipitated carbides in the welded joint were determined by Tecnai G2 F20 transmission electron microscopy (TEM) equipped with energy-dispersive spectrometer (EDS). TEM samples were prepared by a focus ion beam (FIB) machine (FEI Helios 600).

Hardness tests were measured at a ZHV 30 micro Vickers with 500 gf. Tensile tests were conducted on a Zwick Z100 universal testing machine at room temperature (RT), $550{ }^{\circ} \mathrm{C}$, $650{ }^{\circ} \mathrm{C}, 750{ }^{\circ} \mathrm{C}$ and $850{ }^{\circ} \mathrm{C}$, respectively. The geometry of tensile specimens is shown in Fig. 1.

\section{Results and Discussion}

\subsection{Microstructural Characterization of the Welded Joint}

Figure 2 shows the $\mathrm{OM}$ images of $\mathrm{Ni}-28 \mathrm{~W}-6 \mathrm{Cr}$ alloy aswelded joint, which appreciably consists of three regions: base metal (BM), heat affect zone (HAZ), and weld metal (WM) in Fig. 2a. Like many nickel-based alloys, $\mathrm{Ni}-\mathrm{xW}-6 \mathrm{Cr}$ alloy consists of single austenite phase, as well [19]. Microstructure characterization near the fusion line in Fig. 2b shows that the grain in BM is uneven apparently; abundant particles distribute in chains along grain 

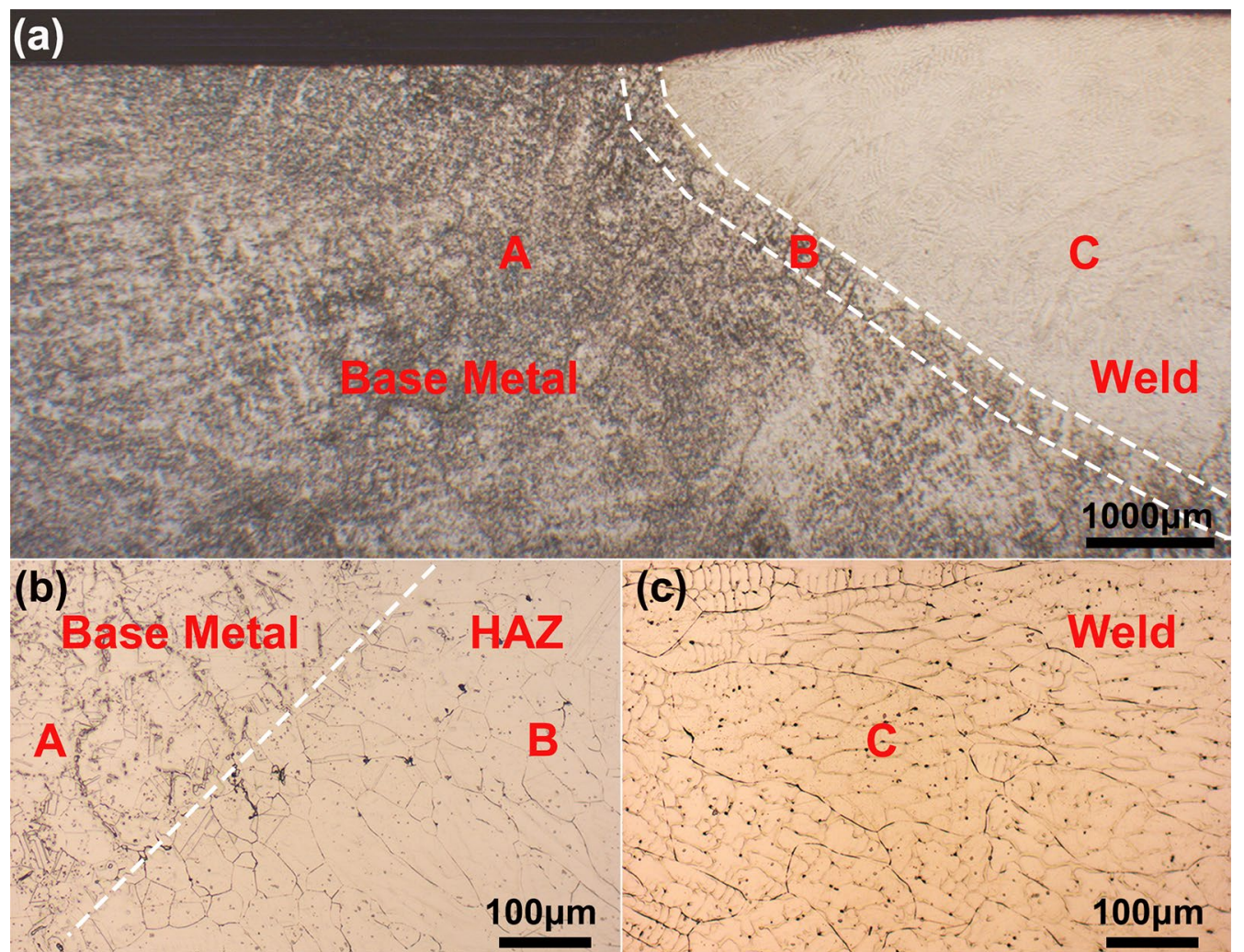

(c)

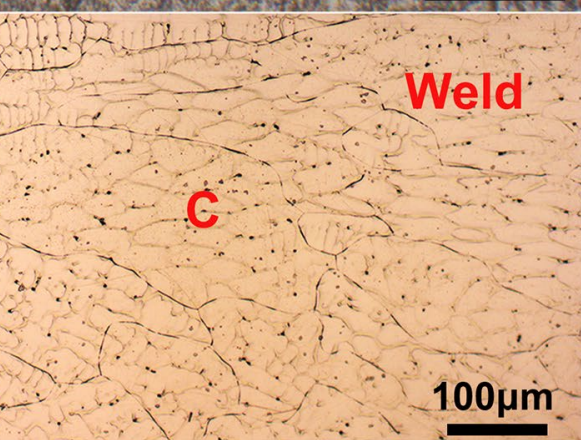

Fig. 2 OM images of microstructure of welded joint: a overall morphology of welded joint, b base metal and HAZ, $\mathbf{c}$ weld metal

boundaries in austenite matrix and vary greatly in shape and size. However, the grain of HAZ is much larger than that of $\mathrm{BM}$. Moreover, almost no evidence of precipitates can be found in HAZ, This indicates that welding process brought a significant effect on the microstructures. Figure $2 \mathrm{c}$ shows typical cast microstructure in the WM, which consists of columnar dendrites and some fine-equiaxed grains. Some tiny precipitates are distributed in the grain boundaries of dendrites, but their number is quite few.

Figure 3 presents high-magnification SEM images of the welded joint. Three different regions, including BM, HAZ, and $\mathrm{WB}$, have significantly different microstructures features, to note that BM has finer grains than that in other regions, as shown in Fig. 3a. From the EBSD map of welded joint in Fig. 3b, the BM consists of fine and equiaxed grains with the average sizes $22 \mu \mathrm{m}$. In addition, it is noted that HAZ near the fusion line turns from fine BM into coarse grain zone (CGZ) after overheating in welding process, and its average grain size increases to $85 \mu \mathrm{m}$. As for the WM, the average grain size is more than $100 \mu \mathrm{m}$, exhibiting a typical coarse cast microstructure. Furthermore, from a higher magnification of BM in Fig. 3c and HAZ in Fig. 3d, numerous stick-like and ball-like particles with sizes ranging from 0.5 to $15 \mu \mathrm{m}$ disperse randomly inside the grains as well as along the grain boundaries. On the contrary, it is hard to detect precipitates in WM, as shown in Fig. 3e.

Figure 4 shows the XRD patterns of both BM and WM of $\mathrm{Ni}-28 \mathrm{~W}-6 \mathrm{Cr}$ alloy, which is single-phase austenite, namely $\gamma$ phase with face-centered cubic (FCC) crystal structure. The characteristic peaks of ( $\left(\begin{array}{lll}1 & 1 & 1\end{array}\right),\left(\begin{array}{lll}2 & 0 & 0\end{array}\right)$, and (2 200$)$ of $\gamma$ phase were clearly detected, which are common phase components in the single austenite nickel-based alloy such as Hastelloy N and Ni-26W-6Cr alloy [20]. As shown in the inset of Fig. 4, the pattern of the BM has the diffraction peaks of $\mathrm{M}_{6} \mathrm{C}$ carbides in addition to those of $\gamma$ phase, while there are no observable diffraction peaks of $\mathrm{M}_{6} \mathrm{C}$ carbides in the XRD pattern of the WM, which is consistent with the microstructure observation in Fig. 3e, which may be due to the low carbide content that is below the detection limit of XRD in WM. Furthermore, in comparison with BM, the characteristic peaks of the alloy matrix significantly shift to lower $2 \theta$ for WM, indicating an increase in lattice parameters. The lattice parameters for $\mathrm{BM}$ and $\mathrm{WM}$ were calculated from the (1 111$),\left(\begin{array}{lll}2 & 0 & 0\end{array}\right)$, and (2 20$)$ peaks according to Nelson-Riley Function [21]. The calculated results suggest that the lattice parameter increases $0.34 \%$ from 3.577 to $3.589 \AA$ after welding. In combination with the notable absence of $\mathrm{M}_{6} \mathrm{C}$ in $\mathrm{WM}$, it indicates that some alloy elements, such as 

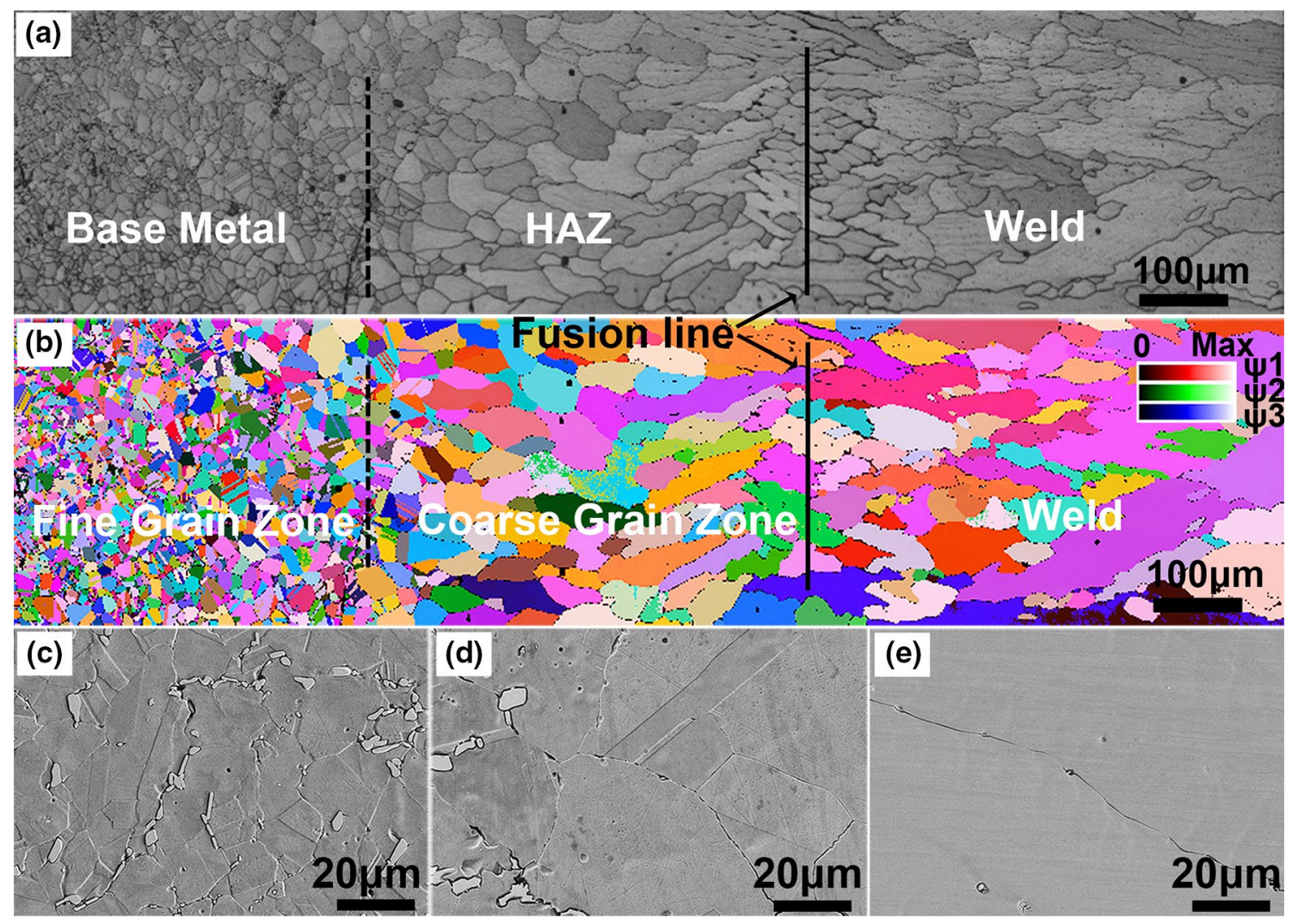

Fig. 3 SEM images a and all-Euler map $\mathbf{b}$ of the welded joint measured by EBSD. Microstructures of BM $\mathbf{c}$, HAZ d, WM e under high magnification

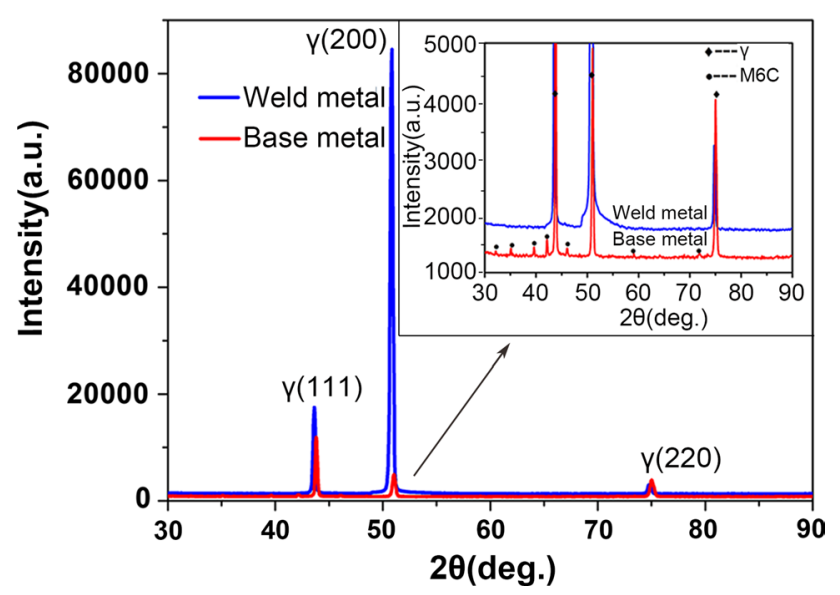

Fig. 4 XRD patterns of base metal and weld metal. The inset was zoomed in to present the characteristic peaks of the carbides

$\mathrm{W}$, are dissolved into $\mathrm{WM}$, leading to the increase of lattice parameter.

To further confirm the existence of carbides in WM and characterize the carbides in the welded joint, SEM and TEM were carried out and the results are shown in Fig. 5. In comparison with the large carbides in BM (Fig. 5a), two kinds of shape of carbides were detected in WM. One carbide locates at the grain boundary with porous surface (Fig. $5 b$ ), whose size is less than $2 \mu \mathrm{m}$, while the other carbide (Fig. $5 \mathrm{c}$ ) is eutectic-like. The selected area electron diffraction (SAED) pattern of carbides in BM (Fig. 5d) clearly matches the pattern of an FCC structure taken on a [110] zone axis, and the lattice parameter was determined to be $11.27 \AA$. As for the two types of precipitates in WM, as shown in Fig. 5e, f, SAED patterns taken on the [-111] and [001] zone axis also both match the pattern of an FCC structure, their lattice parameters were determined to be about $11.10 \AA$, indicating that the carbides with two different morphologies in WM have the same crystal structure.

The chemistry of carbides was determined by TEM-EDS, as shown in Table 3. The previous studies has demonstrated that W-rich $\mathrm{M}_{6} \mathrm{C}$ and Cr-rich $\mathrm{M}_{23} \mathrm{C}_{6}$ (M refers to metal atom) are two common precipitates existed in $\mathrm{Ni}-\mathrm{Cr}-\mathrm{W}$ alloy [20, 22]. Table 3 evidently shows that precipitates in BM and WM have similar chemical compositions and the W contents of the precipitates are much higher than that of BM (Table 3). Thus, these precipitates can be determined as W-rich $\mathrm{M}_{6} \mathrm{C}$ in combination with the results of TEM electron diffraction. It is noted that the mole ratio of $\mathrm{Ni}$ and the sum of other elements $(\mathrm{W}+\mathrm{Cr}+\mathrm{Si})$ in carbides keeps $1: 2$, 

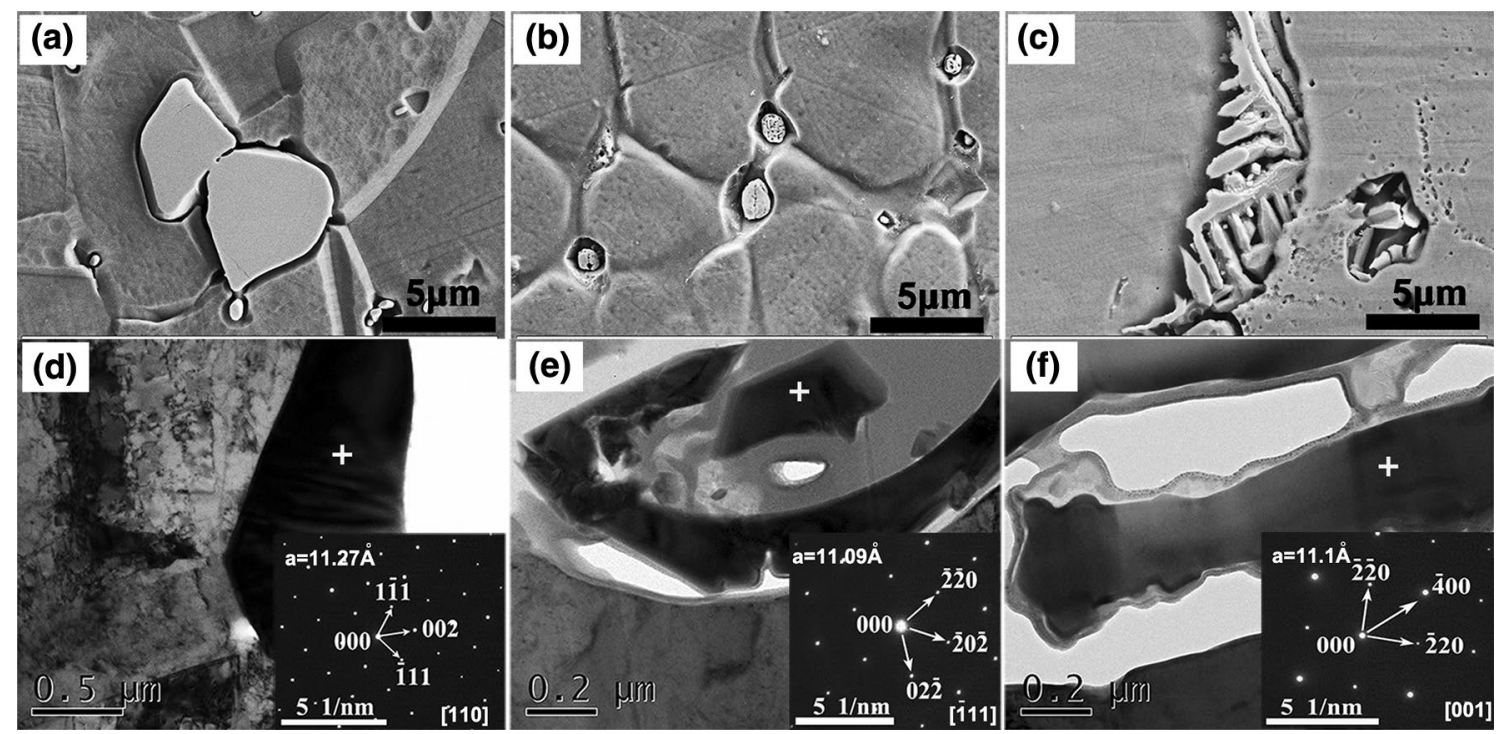

Fig. 5 SEM images and selected area electron diffraction (SAED) pattern of precipitates in different region of the welded joint; a, $\mathbf{d}$ carbides in $\mathrm{BM} ; \mathbf{b}, \mathbf{c}, \mathbf{e}, \mathbf{f}$ carbides in WM

Table 3 Chemical compositions of precipitates in different region of the welded joint by TEM-EDS and the contents of carbon were not detected

\begin{tabular}{lllllll}
\hline Element (at.\%) & $\mathrm{Si}$ & $\mathrm{Ni}$ & $\mathrm{Cr}$ & $\mathrm{W}$ & $\mathrm{Ni}(\mathrm{W}+\mathrm{Cr})$ & $\mathrm{Ni}:(\mathrm{W}+\mathrm{Cr}+\mathrm{Si})$ \\
\hline Precipitates in BM & 24.9 & 31.7 & 7.4 & 36.0 & $1: 1.4$ & $1: 2.2$ \\
Precipitates in weld (particle) & 22.9 & 32.2 & 18.4 & 26.5 & $1: 1.4$ & $1: 2.1$ \\
Precipitates in weld (dentritic) & 22.3 & 32.8 & 17.8 & 27.2 & $1: 1.4$ & $1: 2.0$ \\
\hline
\end{tabular}

indicating that the carbides remain as the $\mathrm{Ni}_{2} \mathrm{M}_{4} \mathrm{C}$ crystal structures [23] during the welding process.

However, the $\mathrm{W}$ contents of $\mathrm{M}_{6} \mathrm{C}$ carbides in the WM $(26.5 \%, 27.2 \%)$ are obviously lower than those of carbides in $\mathrm{BM}(36 \%)$, while the $\mathrm{M}_{6} \mathrm{C}$ carbides in WM possess the higher contents of $\mathrm{Cr}$ and $\mathrm{Si}$ than those in BM. This indicates that the $\mathrm{Cr}$ and $\mathrm{Si}$ atoms tend to substitute for $\mathrm{W}$ atoms in $(\mathrm{Ni}, \mathrm{W}, \mathrm{Cr}, \mathrm{Si})_{6} \mathrm{C}$ rather than $\mathrm{Ni}$ atoms. In addition, the substitution of $\mathrm{W}$ atoms by $\mathrm{Cr}$ and $\mathrm{Si}$ atoms in the carbides leads to about $1.5 \%$ shrinkage of the carbide lattice parameter in WM in comparison with that of the carbide in BM according to the TEM results (Fig. 4e, f).

The difference of chemical compositions between carbides in BM and WM mainly depends on the solidification conditions in welding process. During welding solidification stage, the $\gamma$ matrix takes shape at the solidus temperature above $1400{ }^{\circ} \mathrm{C}$, while normally $\mathrm{M}_{6} \mathrm{C}$ starts to precipitate at about $1300{ }^{\circ} \mathrm{C}$ [24]. Due to the rapid cooling at the initial welding solidification stage, the formation process of $\mathrm{M}_{6} \mathrm{C}$ is nonequilibrium, which should be dependent on the diffusion of constituent elements of $\mathrm{M}_{6} \mathrm{C}$ in the $\gamma$ matrix, i.e., $\mathrm{W}, \mathrm{Cr}$, and $\mathrm{Si}$. The diffusion activation energies of $\mathrm{Si}, \mathrm{Cr}$, and $\mathrm{W}$ in nickel are 2.676, 2.823, and $3.192 \mathrm{eV}$, respectively [25], indicating that the diffusion rate of $\mathrm{Si}$ is much faster than those of $\mathrm{Cr}$ and $\mathrm{W}$, and $\mathrm{W}$ is the slowest one. Thus, at the very start stage, $\mathrm{Si}$ atoms diffuse quickly from the matrix into the carbides content and its content reaches saturation, and then, $\mathrm{Cr}$ and $\mathrm{W}$ atoms compete to occupy the sites of the carbides, leading to the ratio of $\mathrm{Ni}$ to $(\mathrm{W}+\mathrm{Cr})$ in the carbides remains 1:1.4. Therefore, it is reasonable that the $\mathrm{M}_{6} \mathrm{C}$ carbides in WM are rich in $\mathrm{Si}$ and $\mathrm{Cr}$, but lack of $\mathrm{W}$ in comparison with the $\mathrm{M}_{6} \mathrm{C}$ carbides in $\mathrm{BM}$.

\subsection{Hardness of the Welded Joints}

Figure 6 represents the Vickers hardness of the welded joint and corresponding microstructure of the $\mathrm{BM}$ and $\mathrm{WM}$, respectively. Figure 6 a shows the hardness of the WM fluctuates within the range of 190-235 HV. With the distance from weld, hardness value rises dramatically from 240 to about $320 \mathrm{HV}$ in the HAZ and fluctuates around $330 \mathrm{HV}$ in BM. Hardness value in BM is about $100 \mathrm{HV}$ more than that in the WM.

The marked difference in the quantity of carbides between the BM and WM is represented in Fig. 6b, c. Numerous fine $\mathrm{M}_{6} \mathrm{C}$ carbides are in the grain and grain boundaries (Fig. 6b), while there are no or few carbides in WM (Fig. 6c). The previous study [26] showed that $\mathrm{M}_{6} \mathrm{C}$ carbide has significant beneficial effects upon the strength properties, which is in good agreement with the results in Fig. 6. The large 


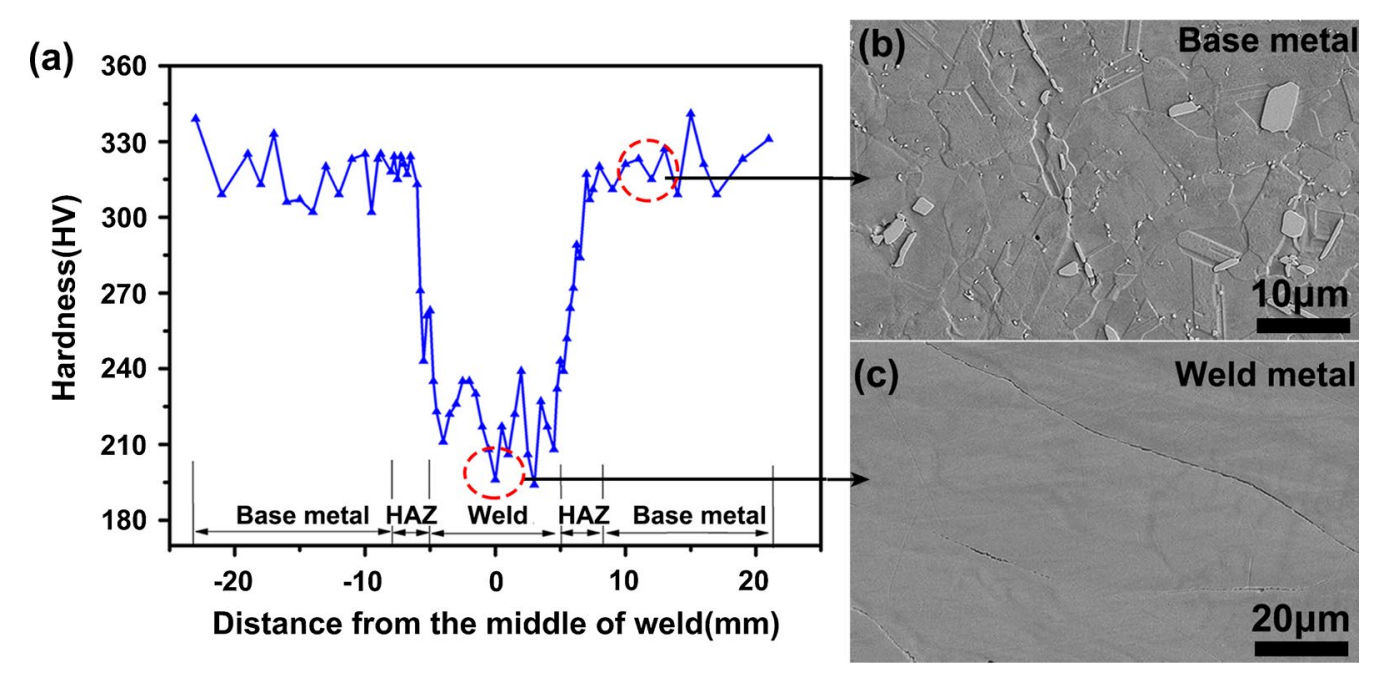

Fig. 6 Hardness and microstructure of the welded joint: a Vickers hardness values varied with the distance; microstructures of the BM b, WM c

number of $\mathrm{M}_{6} \mathrm{C}$ carbides in $\mathrm{BM}$ is considered to obviously improve the hardness, since $\mathrm{M}_{6} \mathrm{C}$ carbides can act as obstacle to retard the movement of dislocation [20]. On the contrary, the absence of carbides in WM (Fig. 6c) seems to be detrimental to the hardness.

\subsection{Tensile Properties of the BM and As-Welded Joints}

Five temperatures including $\mathrm{RT}, 550{ }^{\circ} \mathrm{C}, 650^{\circ} \mathrm{C}, 750{ }^{\circ} \mathrm{C}$, and $850{ }^{\circ} \mathrm{C}$ were selected to evaluate the effects of service conditions on the tensile properties of BM and As-Welded (AW) joints. The results as shown in Fig. 7 indicate BM and $\mathrm{AW}$ specimens have generally the same tendencies in the behavior of the ultimate tensile strengths (UTS), yield strengths (YS), and elongation at different temperature. The strengths and elongation of the alloy are essentially dependent of temperature, decreasing with the increase of temperature.

Figure 7a shows that the YS and UTS of AW specimens are much lower than those of BM, and the gaps of YS between WM and BM are larger than UTS at the same testing temperatures. As temperature increases, the gaps generally become narrower. The YS and UTS of BM decline from 590 and $783 \mathrm{MPa}$ at RT to 198 and $329 \mathrm{MPa}$ at $850{ }^{\circ} \mathrm{C}$, respectively. For AW specimens, their YS and UTS reduce from 416 and $741 \mathrm{MPa}$ at RT to 165 and $192 \mathrm{MPa}$ at $850{ }^{\circ} \mathrm{C}$, respectively. However, elongations in Fig. 7b show a contrary tendency in comparison with strengths that the elongations of AW specimens are larger than those of BM in the range of test temperatures from $\mathrm{RT}$ to $850^{\circ} \mathrm{C}$. In addition, as shown in the inset of Fig. 7b, it should be noted plastic stage mainly occurred in WM for the AW specimens, and all the fracture occurred in WM, indicating that the weakest part of the joint is the WM. Results of tensile tests present a good (a)

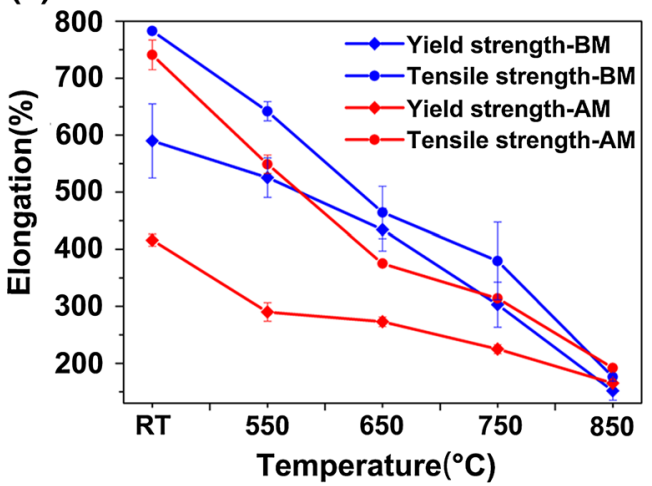

(b)

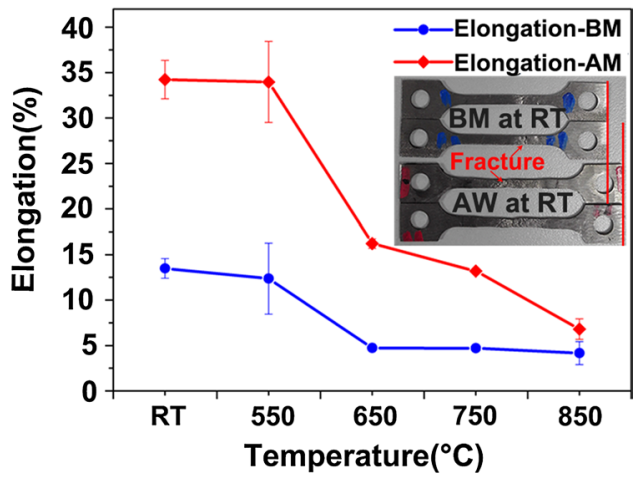

Fig. 7 Tensile properties of welded joints under different temperatures: a yield and tensile strengths, b elongation 
agreement with the hardness measurement that welding process brought lower strength and hardness for Ni-28W-6Cr alloy; this is also primarily due to the absence of $\mathrm{M}_{6} \mathrm{C}$ carbides in WM like hardness change mentioned in Sect. 3.2.

\subsection{Fracture Morphologies of BM and AW Tensile Specimens}

Typical fractures of the BM tensile specimens are illustrated in Fig. 8. Figure 8a, b shows the fracture morphologies after tensile tests at RT and $550{ }^{\circ} \mathrm{C}$, which both share a similar fracture characteristic that dimples and carbides can be distinctly found on the fracture surfaces. Figure $8 \mathrm{c}$ shows typical brittle fracture features with cleavage planes for the tensile specimens at $650{ }^{\circ} \mathrm{C}$. As for the specimens tested at $750{ }^{\circ} \mathrm{C}$ and $850{ }^{\circ} \mathrm{C}$, their fracture morphologies also show brittle features (Fig. 8d, e). Similar fracture morphologies indicate that the tensile specimens may have similar plasticity behavior, which is in good agreement with the tensile tests where specimens at RT and $550{ }^{\circ} \mathrm{C}$ have almost same elongations, as shown in Fig. 7. As for the tensile specimens at $650{ }^{\circ} \mathrm{C}, 750{ }^{\circ} \mathrm{C}$, and $850{ }^{\circ} \mathrm{C}$, they share similar fracture morphologies, and their elongations are all about $5 \%$.

Figure 9 shows the fracture surfaces of AW tensile specimens tested at different temperatures. Fracture surfaces in Fig. $9 \mathrm{a}, \mathrm{b}$ are dominated by dimples which are typical ductile failure like those of $\mathrm{BM}$ at $\mathrm{RT}$ and $550{ }^{\circ} \mathrm{C}$. As test temperature increasing, the brittle fracture feature becomes more visible (Fig. 9c-e), it is evident that the intergranular fracture propagating along the solidification grain boundaries resulted in smooth crystal surfaces. A significant change in the morphology should be noted that no carbides could be detected in the fracture surface of the AW specimens, and
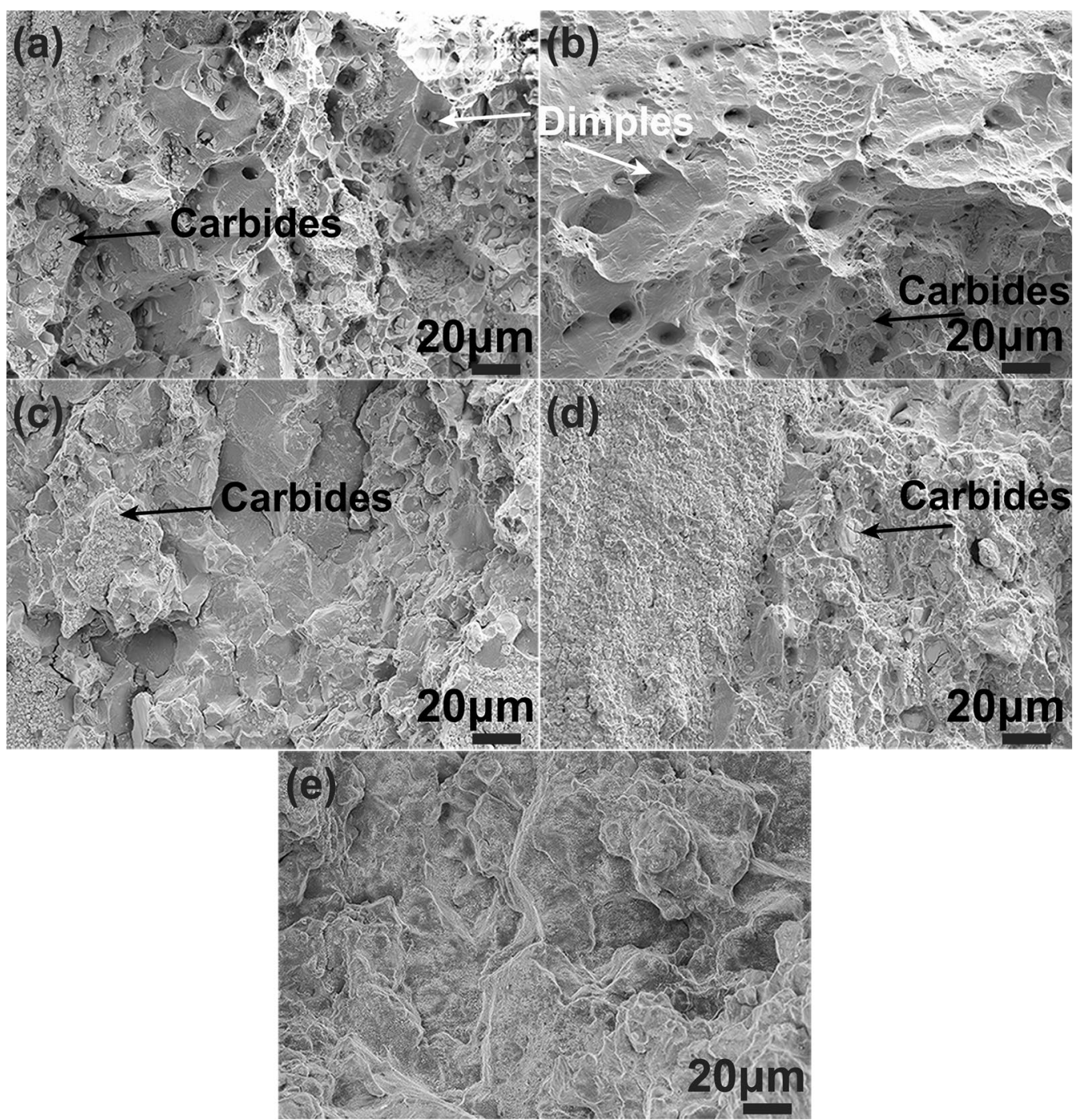

Fig. 8 Fracture morphologies of base metal specimens at a RT, b $550{ }^{\circ} \mathrm{C}, \mathbf{c} 650{ }^{\circ} \mathrm{C}, \mathbf{d} 750{ }^{\circ} \mathrm{C}$, e $850{ }^{\circ} \mathrm{C}$ 

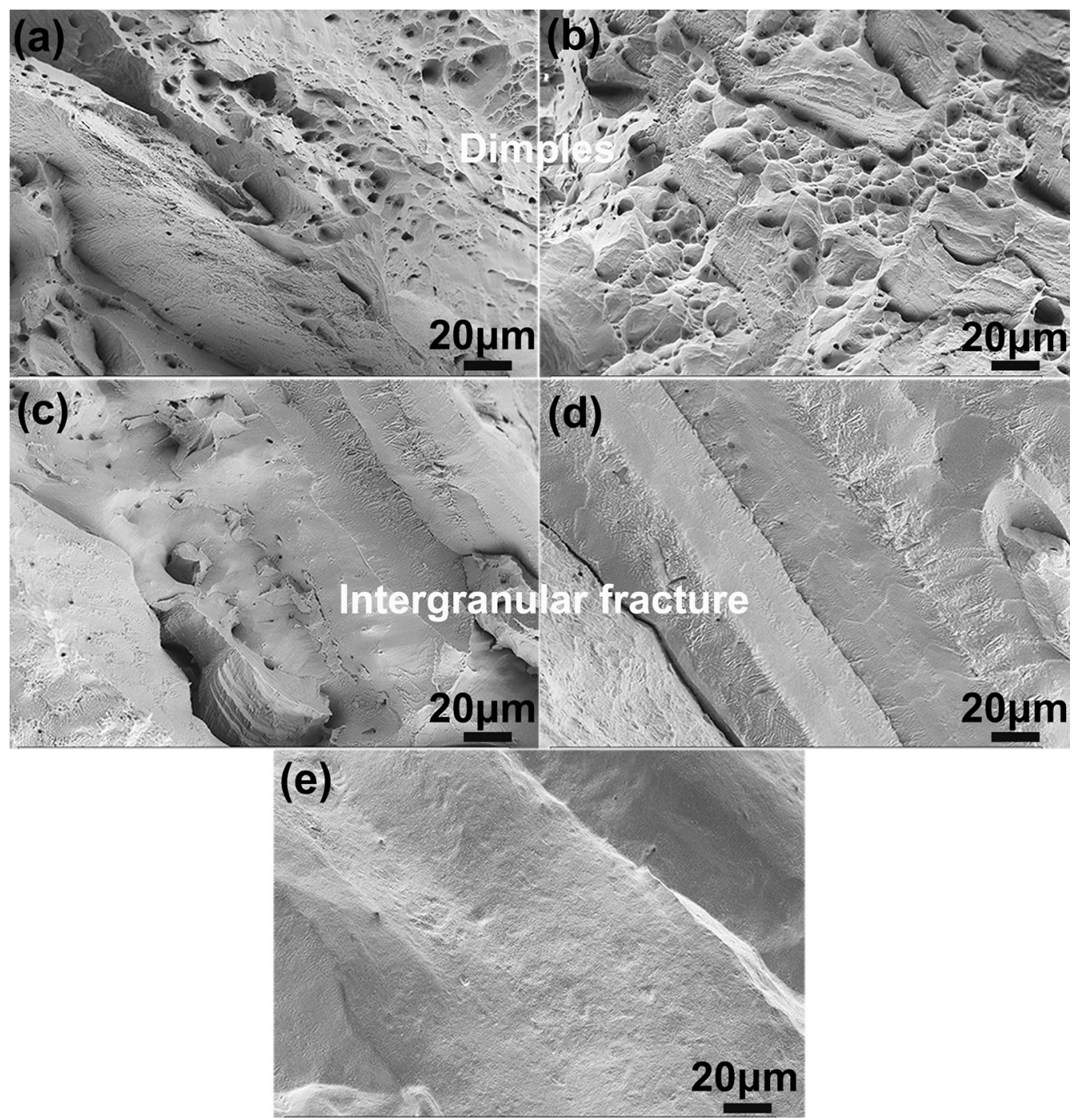

Fig. 9 Fracture morphologies of as-welded specimens at a RT, b $550{ }^{\circ} \mathrm{C}, \mathbf{c} 650{ }^{\circ} \mathrm{C}, \mathbf{d} 750{ }^{\circ} \mathrm{C}$, e $850{ }^{\circ} \mathrm{C}$

these tensile specimens have lower strengths and elongation in comparison with the BM specimens.

By the above analysis on the microstructure and mechanical properties of Ni-28W-6Cr alloy before and after welding, it sounds plausible that the $\mathrm{M}_{6} \mathrm{C}$ carbide have a significant and generally beneficial effect upon the mechanical properties of the Ni-28W-Cr alloy. The hardness of WM is about $60 \%$ of that of BM (Fig. 6), and the YS and UTS are also lower than those of BM, as well. These significant differences are mainly due to the absence of $\mathrm{M}_{6} \mathrm{C}$ carbides in WM. It is generally believed that carbides can hinder the grain boundary sliding and play a role of strengthening to improve the strength of the alloy [27]. Consistent results which have been reported on some other nickel-based alloys showed that $\mathrm{M}_{6} \mathrm{C}$ carbides are beneficial to the mechanical properties, and the strength in particular depends on the quantity of precipitates [26]. Thus, for the BM specimens, it is reasonable for their YS and UTS to be higher than the AW specimens. While carbides in the grain boundaries can also lead to reduction of the bonding strength of the interface. A recent work on Alloy 690 reported that the carbides in grain boundaries fractured and formed a void during the cold working process, which will provide a direct path for crack propagation and cause the final failure [28]. Studies on the $\mathrm{Ni}-\mathrm{xW}-\mathrm{Cr}$ alloy also supported the voids and dislocations are easily piled up around the carbides, which are relatively brittle and could act as nucleation sites of crack, resulting in a lower elongation [7]. Therefore, in view of the tensile tests in this work, it is understandable the BM specimens of $\mathrm{Ni}-28 \mathrm{~W}-6 \mathrm{Cr}$ alloy present lower elongation in than that of AW specimens, as well.

As shown in Fig. 7, the large gaps in mechanical properties between the WM and BW are seriously detrimental to the mechanical homogeneity of welded joint. To solve this 
problem, some feasible methods, such as proper post-weld heat treatment and filler wire with high $\mathrm{C}$ content, could be taken into account to enhance the amount of precipitated carbides, and finally improve the mechanical performance of welded joint of Ni-28W-6Cr alloy. On the other hand, the C content should also be limited to a proper value to guarantee an appropriate ductility of the welded joints.

\section{Conclusions}

1. Welding process can bring some significant changes to the $\mathrm{Ni}-28 \mathrm{~W}-6 \mathrm{Cr}$ alloy, the original fine grains in BM transform into coarse grains in HAZ of welded joint. Carbides in $\mathrm{BM}$ and $\mathrm{WM}$ are both determined as W-rich $\mathrm{M}_{6} \mathrm{C}$; however, the quantity and composition of the carbides in WM change a lot in comparison with those in BM.

2. The $\mathrm{M}_{6} \mathrm{C}$ carbides are proved to have a significantly beneficial effect upon the mechanical properties of the $\mathrm{Ni}-$ $28 \mathrm{~W}-6 \mathrm{Cr}$ alloy. Compared with the high hardness and tensile strengths of BM specimens, the tensile properties and hardness of AW specimens are obviously lower due to the dramatic reduction of carbide in WM.

3. Both BM and AW joints exhibit a ductile fracture behavior below $550{ }^{\circ} \mathrm{C}$, while they show a brittle fracture feature as the temperature reaches above $650{ }^{\circ} \mathrm{C}$.

Acknowledgements The authors wish to thank Professor Chuanyong Cui from Institute of Metal Research, Chinese Academy of Sciences, for his generous support on the supply of $\mathrm{Ni}-28 \mathrm{~W}-6 \mathrm{Cr}$ alloys. This study was funded by the National Natural Science Foundation of China (Grant No. 51601213), National Key Research and Development Program of China (Grant No. 2016YFB0700404), Strategic Priority Research Program of the Chinese Academy of Sciences (Grant No. XDA02004210), and Talent development fund of Shanghai (Grant No. 201650).

\section{References}

[1] R. Serrano-Lopez, J. Fradera, S. Cuesta-Lopez, Chem. Eng. Process. 73, 87 (2013)

[2] C. Prieto, P. Cooper, A.I. Fernández, L.F. Cabeza, Renew. Sust. Energ. Rev. 60, 909 (2016)

[3] X.-X. Ye, H. Ai, Z. Guo, H. Huang, L. Jiang, J. Wang, Z. Li, X. Zhou, Corros. Sci. 106, 249 (2016)
[4] J. Hou, F.-F. Han, X.-X. Ye, B. Leng, M. Liu, Y.-L. Lu, X.-T. Zhou, Acta Metall. Sin. (Engl. Lett.) 1, 12 (2018)

[5] W. Ren, G. Muralidharan, D.F. Wilson, D.E. Holcomb, Considerations of Alloy N for Fluoride Salt-Cooled High-Temperature Reactor Applications. Paper presented at ASME 2011 Pressure Vessels and Piping Conference, Baltimore, Maryland, 17-21 July 2011

[6] H.E. McCoy, The INOR-8 Story. (Report from Oak Ridge National Lab.). https://www.osti.gov/biblio/4766202. Accessed 1969

[7] S. Liu, X.-X. Ye, L. Jiang, C. Cui, Z. Li, H. Huang, B. Leng, X. Zhou, Mater. Sci. Eng. A 655, 269 (2016)

[8] S. Delpech, E. Merle-Lucotte, T. Auger, X. Doligez, D. Heuer, G.S. Picard, MSFR: material issues and the effect of chemistry control. Paper presented at GIF Symposium, Paris, France, 9-10 September 2009

[9] A. Surenkov, Combined materials compatibility: Te corrosion of Ni-based alloys in molten salt fluorides. Paper presented at First ACSEPT International Workshop, Lisbon, Portugal, 03/31-04/02 2010

[10] X. Zhang, D.-Z. Li, Y.-Y. Li, S.-P. Lu, Acta Metall. Sin. (Engl. Lett.) 29, 928 (2016)

[11] J. Yang, Acta Metall. Sin. (Engl. Lett.) 30, 840 (2017)

[12] Z.-Y. Feng, X.-J. Di, S.-P. Wu, D.-P. Wang, X.-Q. Liu, Acta Metall. Sin. (Engl. Lett.) 31, 263 (2018)

[13] H.-L. Ming, Z.-M. Zhang, P.-Y. Xiu, J.-Q. Wang, E.-H. Han, W. Ke, M.-X. Su, Acta Metall. Sin. (Engl.Lett.) 29, 848 (2016)

[14] L.O. Osoba, A.K. Khan, S.O. Adeosun, Acta Metall. Sin. (Engl. Lett.) 26, 747 (2013)

[15] S. Ernst, Weld. J. 73, 80 (1994)

[16] F. Meyer-Olbersleben, N. Kasik, B. Ilschner, F. Rézaï-Aria, Metall. Mater. Trans. A 30, 981 (1999)

[17] C.A. Schuh, T.G. Nieh, H. Iwasaki, Acta Metall. 51, 431 (2003)

[18] J.N. DuPont, J.C. Lippold, S.D. Kiser, Welding metallurgy and weldability of nickel-base alloys (John Wiley \& Sons, New Jersey, 2009), pp. 100-143

[19] S. Chen, X.-X. Ye, D. Tsang, L. Jiang, K. Yu, C. Li, Z. Li, J. Mater. Sci. Technol. 35, 29 (2019)

[20] L. Jiang, X. Ye, C. Cui, H. Huang, B. Leng, Z. Li, X. Zhou, Mater. Sci. Eng. A 668, 137 (2016)

[21] J.B. Nelson, D.P. Riley, Proc. Phys. Soc. 57, 160 (1945)

[22] H.J. Lee, H. Kim, D. Kim, C. Jang, Mater. Charact. 106, 283 (2015)

[23] M. Fiedler, H. Stadelmaier, Z. Metallkd. 66, 402 (1975)

[24] Y. He, J. Yang, S. Chen, Z. Gao, Vacuu 125, 26 (2016)

[25] G. Neumann, C. Tuijn, in Self-diffusion and impurity diffusion in pure metals: handbook of experimental data (Elsevier, London, 2011), pp. 128-129

[26] H.E. Collins, Metall. Trans. 5, 189 (1974)

[27] S. Chen, X.X. Ye, K. Yu, C. Li, Z. Li, Z. Li, X. Zhou, Mater. Sci. Eng. A 682, 168 (2017)

[28] Q.J. Peng, J. Hou, T. Yonezawa, T. Shoji, Z.M. Zhang, F. Huang, E.H. Han, W. Ke, Corros. Sci. 57, 81 (2012) 